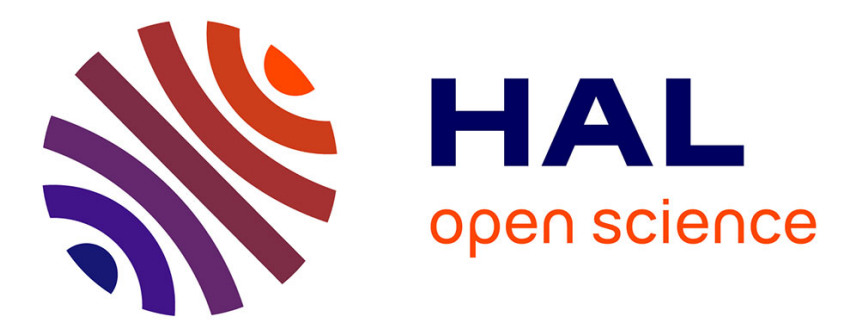

\title{
Would fewer people drive to work in a city without excess commuting? Explorations in the Paris Metropolitan Area
}

\author{
Emre Korsu, Florent Le Néchet
}

\section{- To cite this version:}

Emre Korsu, Florent Le Néchet. Would fewer people drive to work in a city without excess commuting? Explorations in the Paris Metropolitan Area. Transportation Research Part A: Policy and Practice, 2017, 95, pp.259-274. 10.1016/j.tra.2016.10.030 . halshs-01527513

\section{HAL Id: halshs-01527513 https://shs.hal.science/halshs-01527513}

Submitted on 24 May 2017

HAL is a multi-disciplinary open access archive for the deposit and dissemination of scientific research documents, whether they are published or not. The documents may come from teaching and research institutions in France or abroad, or from public or private research centers.
L'archive ouverte pluridisciplinaire HAL, est destinée au dépôt et à la diffusion de documents scientifiques de niveau recherche, publiés ou non, émanant des établissements d'enseignement et de recherche français ou étrangers, des laboratoires publics ou privés. 


\title{
Would fewer people drive to work in a city without excess commuting? Explorations in the Paris Metropolitan Area.
}

Korsu Emre, Le Néchet Florent

Université Paris-Est, Laboratoire Ville Mobilité Transport, UPEMLV : 5 boulevard Copernic, Cité Descartes F 77454 Marne-la-Vallée cedex 2 France

Corresponding author : emre.korsu@enpc.fr

Korsu, E., \& Le Néchet, F. (2017). Would fewer people drive to work in a city without excess commuting? Explorations in the Paris metropolitan area.

Transportation Research Part A: Policy and Practice, 95, 259-274.

https://doi.org/10.1016/j.tra.2016.10.030

\begin{abstract}
Urban planners have explored many solutions for reducing the energy and environmental costs of daily mobility in cities and one of them is to encourage households to embrace more efficient commuting patterns. As research on "excess commuting" has shown, the spatial distribution of housing and jobs in many cities would theoretically allow much shorter commuting distances than are actually observed. The question this paper tackles is how a more efficient commuting pattern would affect the transport modes workers use to travel to work. If workers and jobs were rematched in such a way as to minimise average commute distance, how would such a change impact the way people travel to work? While one might easily imagine an increase in the share of trips covered by soft modes of transport, there are reasons to believe that in some cases there might also be unexpected outcomes such an increase in car use. So how would people travel to work in a city where there is no "excess commuting"? We looked for an answer to this question through empirical simulations in the case of the Paris Metropolitan Area.
\end{abstract}

\section{Highlights}

- An original way to explore the issue of excess commuting

- A simulation-based approach to estimating the share of car use in trips-towork under the hypothesis of commute minimisation

- Pioneering research on excess commuting in the case of the Paris Metropolitan Area 
- In the Paris Metropolis, cutting average commuting distance could result in an increase in commuting by car

- Minimising commute length converts many long-range trips by public transport into mid-range trips by car

Key-words: excess commuting, daily mobility, car use, public transport, modal shift, Paris

\section{Introduction}

The distances people living in cities travel on a daily basis, especially by car, has increased greatly since the 1970s (cf. Lee et al. (2009), Nielsen et al. (2005), Frändberg and Vilhelmson (2011), Massot and Roy (2004) for trends in different countries). This trend has led to greater energy consumption from urban mobility and rising greenhouse gas emissions. Urban planners can call on a portfolio of solutions to counter these trends: the development of efficient alternatives to the car and of cleaner and more energy-efficient vehicles; changes to road network design in order to reduce speed and capacity; tax measures affecting the cost of travel; planning efforts to locate employment and housing in places well served by public transport (Banister, 2008). An alternative solution is to encourage households to make residential location choices that bring the origins and destinations of their daily trips, particularly the home and workplace, closer to one another. In theory, this should be an effective strategy for shortening daily trips, especially trips-to-work. The research on "excess commuting" has produced a large number of empirical studies which have stimulated discussion about the practical effectiveness of this strategy. The aim of this research is to calculate the shortest average commute distance possible in a city, given the spatial configuration of housing and workplaces, by finding a different match between workers and jobs. The difference between the average actual commute and the theoretical minimum is defined as "excess" or "wasteful" commuting.

Since the seminal studies by Hamilton (1982) and White (1988), the volume of research on excess commuting has grown year on year (Cropper and Gordon, 1991; Small and Song, 1992; Giuliano et Small, 1993; Kim, 1995; Merriman et al., 1995; Frost et al., 1998; Horner, 2002; Horner and Murray, 2002; Manning, 
2003; O'Kelly and Lee, 2005; Niedzielski, 2006; Ma and Banister, 2007; Charron, 2007; Yang, 2008; O'Kelly and Niedzielski, 2009; Murphy, 2009; Horner, 2010; Loo and Chow, 2011; Boussauw et al., 2011; Suzuki and Lee, 2012; Chowdhury et al., 2013). This research has shown that, in many urban contexts, the theoretical minimum commute is only a few kilometres, suggesting that current levels of excess commuting are substantial $(40-50 \%$ of observed commute distances) (Horner, 2007).

Discussions on the excess commuting issue have focused mainly on the interpretation of the results and their implications for scientific knowledge and public policy. They have also taken the form of critical reflections about the robustness of the results (cf. Ma and Banister (2006) for a critical metaanalysis). Conceptual and methodological improvements and sophistications were introduced on the basis of additional concepts and indicators such as the theoretical maximum average commute, commute range, capacity utilization, and average random commute, which enriched the reflection on the commute efficiency issue (Horner, 2002; Charron, 2007; Murphy and Killen, 2011). In alternative studies (O'Kelly and Niedzielski, 2008), the issue was addressed from a different perspective, centred on the measure of the effort needed to reduce average commute length and exploring the way this task appears to be more or less achievable according to the spatial structure of cities. Some authors (Merriman et al., 1995; Horner and Murray, 2002; Layman and Horner, 2010) have also explored the changes that need to be made to the urban fabric to help cities move closer to the post-min model. ${ }^{1}$ Similarly, approach by Horner (2008) tried to reduce the gap between excess commuting literature and urban form literature by seeking the set of flows and simultaneously the increase in numbers of workers and employments for each zone that would minimize the total commuting distance. In all likelihood, our cities will never match this model in reality, as stated by O'Kelly and Niedzielski (2008), but public interventions on land-use, transport, mobility and the job market could potentially have an impact and bring actual commuting distances closer to the theoretical minimum. Job deconcentration, development of residential facilities closer to employment centres, investment in public transport facilities, tax measures on travel costs,

1 We use the term "post-min" to refer to a virtual city where the average commute length is minimised - post-min meaning after the minimisation of total commuting distance. 
more efficient matching of workers and jobs, are some of the potential incremental ways of achieving this target.

Up to now, little attention has been paid to the post-min city's characteristics in terms of energy consumption, greenhouse gas emissions or commuting transport modes. The research by Scott, Kanaroglou and Anderson (1997) and Welch and Mishra (2014), who developed simulation models to estimate the level of congestion and greenhouse gas emissions in the post-min city, are major but rare contributions to such a project. Yet such analyses are surely useful if the post-min city is a model to which urban policy seeks to aspire. The aim of the research presented in this paper is to explore the post-min city's characteristics in terms of travel mode choice on trips-to-work. How would workers travel to work in a city with no excess commuting? If jobs and workers were matched to maximum efficiency, which transport modes would be most frequently used, and which would lose market share?

This question is all the more interesting in that there may well be unexpected outcomes. For obvious reasons, one can imagine the post-min city to be perfectly suited to soft modes and public transport. As mentioned above, previous research on excess commuting showed that in many cities, the minimum average commute length is quite small, in some cases only a few kilometres. This suggests that a significant proportion of commutes in the postmin city would consist of short trips, which could potentially be covered by soft modes or public transport. However, as we will discuss, under particular conditions - depending on the relative performances of public transport and car travel on mid-range and long commutes, and on the way the minimisation of average commute length reshapes the distribution of commuting distances the post-min city could, paradoxically, also lead to a rise in commuting by car.

The research is applied to the case of the Paris Metropolitan Area (PMA). Using data from the French Census and from the Comprehensive Transport Survey (CTS - Enquête Globale sur les Transports), we conducted simulations to estimate the modal split in trips-to-work in the post-min PMA, that is after commuting distances have been minimised through the rematching of workers and jobs. By comparing the post-min modal split with the existing distribution, 
we were able to evaluate how a shift towards the post-min city would impact modal choice on trips-to-work in the PMA.

Before going any further, we would like to underline here that the aim of our research is mainly to give some insights into what the post-min city model might look like. For obvious reasons, the results shown in the following pages cannot pretend to represent exactly the way things would go if commute length was minimised in the PMA. There is no doubt that when trends occur for real, the urban system reacts, the socioeconomic actors modify their behaviour in response, new policies are conceived and implemented, and these changes affect the trends themselves. The simulations we have produced aim to provide some basic markers to feed into thinking about the characteristics of the postmin city and are a way to identify some of the trends that might be observed, ceteris paribus, if workers commuted more efficiently.

The paper is organised into four sections. In the first section, we explore theoretically the potential impact of minimising commute length on the modal choice of workers in their trips-to-work. The second section sets out the methodology designed for the purpose of our analysis and the data used. In the third section, we present the main results and, in the final section we discuss the implications of our findings for urban policy.

\section{The modal share of transport modes in the post-min city: a discussion}

Considered as a model, the post-min city looks very positive. One imagines it as a city of short trips, where most inhabitants have the opportunity to live near their jobs. Consequently, one would expect it to make more room for soft modes of transport such as walking or cycling, since the distances that need to be covered are shorter overall. The post-min city could therefore be expected to be a clean and energy-efficient city, free of excessive car mobility.

However, if one thinks in terms of modal split for trips-to-work, there are reasons to think that the balance of the post-min city may be more complex to forecast than might be assumed a priori. When workers and jobs are virtually rematched to minimise commute distances, the process produces a leftward 
shift in the distribution of trip length, meaning fewer long-distance commutes. In many cities across the world, public transport is quite an efficient method of long-distance commuting and attracts significant market share. This is true, for instance, in a number of European cities such as Paris or London, where extensive rail transit networks are highly competitive in connecting the city centre and the outer suburbs.

In the Paris metropolis, public transport captures a greater market share than the car for long-distance commuting (Le Néchet, 2012). London, with a dominantly radio-concentric urban structure, has characteristics similar to Paris: long-distance public transit trips connecting Inner London and the South-East account for up to $80 \%$ of the market (Mayor of London report, 2006). Figures from Schwanen et al. (2001) in the Netherlands allow to compare the relative performance of transit and automobile for various kinds of mobility patterns. The share of transit is higher for "decentral" type of commuting pattern, which tend to be long trips, a prevalence of symmetric radial flows around the centre. Conversely, transit shares are lower for "cross-commuting" flows, which tend to be shorter, as they are a part of local mobility pattern reminding the "urban villages" of Bertaud (2004). In other countries, of course, public transport is not so competitive on long-distance trips and the car continues to dominate this market segment as well. In the United States, the proportion of trips to work covered by car reaches $90 \%$ at the 4 mile threshold, and never drops below this percentage as commute length increases, according to the 2009 National Household Travel Survey. In the polycentric Rhine-Ruhr region, in Germany, car is increasingly dominant for long commuting trips (Le Néchet, 2012). In German cities overall, the car consistently accounts for more than $80 \%$ of all journeys longer than 10 kilometres (all purposes), according to the 2008 Mobilität in Deutchland survey.

Table 1 shows the modal split for transport modes on trips-to-work in the PMA according to the 2001/2002 CTS. The share of public transport (exclusively rail, exclusively bus and combination of rail and bus), and the combination of public transport and private car reaches its peak level on commutes longer than 25 kilometres (given that in this kind of long-distance commuting, public transport and the private car are combined on journeys where most of the distance is 
covered by public transport, the car being used for a shorter trip to access the PT network). Beyond the 25 kilometre threshold, the majority of commutes are travelled partly or exclusively by public transport, which is not the case for commutes shorter than 10 kilometres.

In conditions of this kind, where public transport captures significant market share on long commutes, the fall in the number of long trips-to-work after average commute length is minimised would mean the loss of many journeys currently covered by public transport. So fewer long-distance commutes does not necessarily lead to fewer car journeys; it can also mean fewer trips by public transport. But this statement applies only to metropolitan areas where the specific conditions we mention are met. In cities where the share of public transport is not an increasing function of trip distances, the reduction of commute distances can result in a decrease in car-use on trips-to-work. So the specific pattern where the minimization of commute length leads to a larger market share for car on commutes should not be considered as a general model. Nevertheless, as there seems to be other metropolitan areas where public transport catches an increasing market share as commute distances become longer, the results obtained in the case of the Paris metropolis could well apply to other cases.

The decrease in the number of long commutes can correlate with an increase in the number of short trips-to-work, but it can also lead to an increase in the number of mid-range trips. In many cities, the most competitive transport mode on mid-range trips is the private car. This is the case in the PMA, as can be seen in Table 1: almost half of the commutes between 2.5 and 10 kilometres are travelled exclusively by car - the car's market share is at its highest on this distance range. Consequently, if the shift to the post-min city were to make midrange commutes more frequent, this could well produce upward pressure on car use for trips-to-work. At the same time, this impact could be offset or outweighed by upward pressure on the use of soft modes of transport or public transport reflecting the increase in the number of short trips-to-work. Soft modes of transport or public transport modes like the bus, subway or tram, capture 
significant market share on short commutes. ${ }^{2}$ Therefore, alongside the pro-car impact suggested above, the post-min city could also boost short journeys-towork travelled on foot, by bike, bus, subway or tram. But as the car also captures significant market share on short commutes, it must also be considered that a portion of the increase in the number of short-range trips-towork is likely to be absorbed by car use (in the PMA, 30\% of the shortest commutes - a kilometre or less - are still travelled by car exclusively; cf. Table 1). These considerations suggest that minimising commuting distances can theoretically produce opposing trends, in some cases encouraging car use for trips-to-work, in others favourable to public transport and soft modes of transport.

From a theoretical perspective, the market shares of the different transport modes on trips-to-work in a post-min version of a given city are likely to depend on two parameters: (i) the variation in market share between different transport modes according to commute length in that city, (ii) the way minimising commute length modifies the distribution of commuting distances. Depending on how these two parameters combine, the post-min city may be conducive to soft modes of transport as might be expected, but might paradoxically also appear more cluttered with cars. Consequently, the post-min city's balance in terms of modal split on commuting journeys is largely a matter of empirical evaluation. This balance may vary significantly depending on the urban context.

Observations in the Paris metropolitan area provide some empirical support for the idea that shorter commuting distancgs may in fact lead to more frequent car use for trips-to-work. Using data from the 2008 census, we looked at the way the proportion of car trips changed in localities where the average commute length was initially high (greater than 20 kilometres), and then separated places where the commute length shrank between 1999 and 2008 from those where it grew. The findings showed that car use gained ground against public transport more frequently and to a greater extent in areas where the average commute length decreased. This result reinforces the idea that shortening commuting distances can stimulate car use at the expense of public transport.

\footnotetext{
2 In large German cities, for instance, more than $50 \%$ of all trips under one kilometre, and still around $20 \%$ between two and three kilometres, were travelled by soft modes of transport in 2002 (Scheiner, 2010)
} 
The possibility of a modal shift from public transport to car in the post-min city has a number of implications. It would mean that the post-min city model might also have potential weaknesses, specifically in the field of transport. While reducing many negative external effects caused by car use (high levels of energy consumption and greenhouse gas emissions), the post-min city could potentially exacerbate others: greater need for parking lots, more congestion locally, especially on the secondary road network (though this is only a possibility: the geography of trips in the post-min city and reduced trip distances could also lead to less urban congestion), growing need for household car ownership. True, the benefits of the post-min city in terms of energy consumption and greenhouse gas emissions could far outweigh these potential costs associated with a rise in car use. However, we feel that it is still worthwhile exploring whether such costs are inevitable.

\section{Methodology}

Our research is a case study on the Paris Metropolitan Area (Aire Urbaine de Paris). The PMA is a large metropolitan region encompassing 12 millions inhabitants and 5 millions jobs in an area of $12,000 \mathrm{~km}^{2}$. It consists of a main central conurbation, with very high densities, especially in the inner-city, and an extended suburban ring with small towns and rural-like low-density areas (Figure 1). The average commute distance in the Ile-de-France region ${ }^{3}$ was 11 kilometres in 2008, $43 \%$ of trips-to-work were covered by car and a similar proportion (42\%) by public transport (Caenen et al., 2011).

The investigations are based on data from two different sources, the 1999 Census by the National Institute of Statistics and Economic Studies (Institut National de la Statistique et des Etudes Economiques - INSEE) and the 2001/2002 Comprehensive Transport Survey (CTS - Enquête Globale sur les Transports) conducted jointly by the INSEE and the Regional Directorate of Planning in the Ile-de-France Region (Direction Régionale de l'Equipement en Ile-de-France - DREIF). The Census provides detailed information on the location of workers and employment at municipal scale and on the

\footnotetext{
${ }^{3}$ The lle-de-France region corresponds to the administrative boundary of the Région, which is an administrative and political body. It includes most of the inhabitants and economic activities in the PMA. Usually, statistics on travel patterns from transport surveys are only available at the scale of the lle-de-France region.
} 
characteristics of workers (socio-professional status and educational attainment). The CTS is a survey based on a sample of 10,000 households representing the population of the lle-de-France region randomly selected from the National Population Census and interviewed about their travel practices. It contains information on travel patterns (origin and destination of trips, distances travelled, travel time, purpose of trips, modes of transport used) and also provides more accurate details of the transport modes used in daily trips than the National Census - for instance, the CTS differentiates rail travel from bus travel, trips on foot/bicycle from motorcycle trips. The CTS is also valuable for the detailed information it provides on multimodal journeys. This is important within the context of our research because it gives more detailed results on the transport modes that would be used in trips-to-work in a post-min PMA, allowing more in-depth discussion of the potential transport issues relating to the process of commuting minimisation.

\section{Figure 1}

The methodological framework unfolds in a number of steps. The aim of the first step is to generate virtually, on computer, the post-min Paris MA. We minimised the average commute length using the standard "Transportation Problem" algorithm provided with TransCAD software. The procedure consists in rematching workers and jobs, within worker and job profile constraints (not any worker is matched with any job), in such a way that the average commute length which results is the shortest possible.

In mathematical terms, the aim is to minimize, separately for various groups of workers, the following $D$ function, with the flow $n_{i j}$ between zones $i$ and $j$ (necessarily a non-negative figure) operating as the adjustment variable:

$$
D=\sum_{i=1}^{N} \sum_{j=1}^{N} d_{i j} n_{i j}
$$

under constraints:

$$
\forall 1 \leq i \leq N, \sum_{j=1}^{N} n_{i j}=W_{i}
$$




$$
\forall 1 \leq j \leq N, \sum_{i=1}^{N} n_{i j}=E_{j}
$$

with:

$N$ : total number of zones,

$W_{i}$ : number of workers living in zone $i$,

$E_{j}:$ number of jobs for workers located in zone $j$,

$d_{i j}$ : distance between zones $i$ and $j$

When journeys-to-work are minimized, the long distance metric (trips longer than 10 kilometres in the case of Paris), compatible with heavy rail transit systems, may lose ground to the benefit of mid-range distance metric (3-10 kilometres), more compatible with car. The following diagram (Figure 2) illustrates this potential process with a simple example.

\section{Figure 2}

It is important to emphasize that such a modal shift could occur even if private car is the most commonly used mode of transport on long distance commutes, as long as its modal share is decreasing beyond a given distance threshold to the benefit of public transport.

At the end of the process, we obtained the flow of trips-to-work between and inside zones in the post-min Paris MA: the total number of workers living in zone $i$ and working in zone $j$ is known for all zone pairings $i j$. Following the work of Horner (2002), among others, the re-matching between workers and jobs was performed separately for different groups of workers. The latter were classified into ten groups on the basis of socio-professional status and educational achievement (5 levels of socio-professional status $\times 2$ levels of educational achievement). The socio-professional statuses are: executive managers, superior intellectual professions and chief executives of companies with more than ten employees; intermediate professions; clerks and salesmen; blue-collar workers; craftsmen and merchants. In the first two socio-professional groups, workers with a college degree form the group with high educational achievement, the remainder the group with low educational achievement. For 
the last three socio-professional groups, the group with high educational attainment encompasses workers with a high school diploma whereas the loweducation group covers workers without a high school diploma.

The basic spatial units are the 1603 municipalities belonging to the PMA in 1999. Our estimate of excess commuting is therefore highly disaggregated. This significant number of zonal units reduces the risk of underestimating excess commuting as a consequence of MAUP issues (cf. Horner and Murray, 2002; Niedzielski et al., 2013). To calculate the commute length when both the origin and the destination were within the boundaries of a municipality, we used the following equation estimated by Mercier (2007) in the French context:

Intra-zonal trip distance $=0.44+0,58{ }^{*} r$

Where $r$ is the radius of the municipality

Euclidean (straight-line) distance was used for inter-municipality trips. The data on the number of workers and jobs in municipalities are taken from the 1999 French National Census.

The objective of our research is to estimate the number and proportion of tripsto-work which would be covered by different transport modes in the post-min PMA and compare the assessment with the existing PMA. To do this, we built a methodology based primarily on the CTS. Using data from the latter survey, we estimated a regression model where the dependent variable is the main transport mode used on trips-to-work by workers in the PMA and the explanatory variables are the area of residence, the area of work and the distance between home and work. The sample encompasses the first non-stop journey to work of the day $(n=6700)$. The dependent variable is designed as a polytomic nominal variable with seven modalities: public rail transport exclusively (possibly combined with soft modes at the start or end of the journey); public bus exclusively (possibly combined with soft modes); combination of public rail transport and bus; private car (PC) exclusively; combination of PC and public transport; motorised two-wheelers exclusively; soft modes of transport exclusively. We divided the areas of residence and work into five zones: Paris intra-muros (the inner city); inner suburbs; outer suburbs; peripheral urban conurbations; low-density periurban areas (Figure 1). The 
distances between home and work were broken down into seven discrete classes: less than 1 kilometre; 1 to $2.5 \mathrm{~km}$; 2.5 to $5 \mathrm{~km} ; 5$ to $10 \mathrm{~km}$; 10 to $25 \mathrm{~km}$; 25 to $40 \mathrm{~km}$; more than $40 \mathrm{~km}$. A sensitivity analysis was conducted on the breaks and we chose intervals that ensured strong explanatory power for the model while containing only a few classes (counting each a sufficient number of observations).

As the probability of a trip-to-work being travelled by the different modes of transport is likely to vary depending on socio-professional status, we estimated separate models for two groups of workers: a high-income group on the one hand (executive managers, superior intellectual professions, chief executives of companies with more than ten employees, intermediate professions), a lowincome group on the other (clerks, salesmen, blue-collar workers, craftsmen and merchants). Both models are consistent and perform well (cf. Table A1 in the appendix). The estimated coefficients enabled us to calculate the likelihood of each transport mode being used to travel to work, given the workers' zones of residence and of work and the distance between home and workplace. ${ }^{4}$

Obviously, this modal choice model is rather rudimentary as it contains a very limited number of variables. The factors that determine individual transport mode choice are much more diverse and also include socio-demographic characteristics such as age, gender, family status, etc. The addition of such variables to the model would have enhanced its efficiency, but this option does not fit in with the framework of our research. The main function of the modal choice model in our research is to help us to estimate the number of trips-towork travelled with each mode of transport in the real city and in the post-min city. Commute length minimisation is conducted from a macro-perspective and the output is O/D flows for ten groups of workers. All we know about workers travelling from one zone to another in the post-min city is their places of residence and work, the distance between these two places, their socioprofessional status and their educational background. Their other

\footnotetext{
${ }^{4}$ In this approach, the estimates calculated with data from the CTS survey are then applied to calculate probabilities at the scale of the PMA. The CTS covers the lle-de-France region which is slightly smaller than the PMA in terms of population but the difference is not very big. The lle-de-France region (10.9 million inhabitants in 1999) represents a very important share of the PMA (11.1 millions inhabitants at the same date). Consequently, it is not very likely that estimates calculated at the scale of the PMA would be very different from those estimated at the scale of the lle-deFrance region.
} 
characteristics remain unknown. That is why our modal choice model is solely based on these few variables (socio-professional status, zone of residence, zone of work and commute length as explanatory variables).

The probabilities derived from the two regression models are used to disaggregate the trips-to-work between O/Ds according to the main mode of transport used, for each socio-professional status. This is applied to observed commutes in the PMA and to commutes after minimisation of the average commute length. At the end of the process, we obtain an estimate of the number of commutes completed with each transport mode between all origins and destinations in both the actual PMA and the post-min PMA.

This broad procedure is implicitly built on the assumption that the modal choices of workers in the post-min city would continue to be governed by the same determinants and parameters as in the real city. This implies other assumptions such as the stability of the public transport supply or the invariance of trip durations by car in the transition to the post-min city. In reality, one can expect both travel demand and supply to be significantly affected by the change in the commuting geography which would occur if the average commute length was minimised. We discuss the implications of this issue in the final section of this paper.

The main advantage of the CTS as a data source is, as previously mentioned, higher quality information on the transport modes people use on their trips-towork. Its drawback is that it provides sample-based information which demands the use of regression techniques to estimate the number of trips-to-work between each O/D. This approach leads to a substantial level of approximation: to determine the modal split of trips-to-work between each two municipalities, we rely on estimates calculated on the basis of trips-to-work between the larger areas (inner-city, suburbs, etc.) in which these municipalities are located.

This methodological limitation prompted us to develop an alternative approach based on National Census data. The data set from the Census contains a much larger number of observations (an approximate total of 230,000 commutes) than the CTS sample. The huge number of observations provides direct information on the transport modes workers use on their trips-to-work between any two 
municipalities in the PMA without any intermediate regression analysis. The observed modal split on trips-to-work between any two municipalities is then used to estimate the transport modes on trips-to-work in the post-min PMA. The drawback of the census data is that they provide poorer information on the transport modes used on trips-to-work (no distinction between different types of public transport, between motorised and non-motorised two wheelers, a rather undefined category covering all multimodal trips). So this second approach is employed mainly as a complementary analysis to test the reliability of the results produced by the main CTS based approach. The results presented in the next section are those obtained through the primary methodology built on data from the CTS. The secondary approach based on the Census data broadly confirmed these primary results.

\section{How would workers travel to work in a post-min Paris MA?}

As expected, the re-matching of workers and jobs in order to minimise average commute distance profoundly reshapes the distribution of journeys-to-work based on trip length (Table 2). The very long trips almost entirely disappear (only $2.3 \%$ of trips-to-work in the post-min PMA are longer than 20 kilometres as against $21 \%$ in the real city), long trips become rare (less than $10 \%$ of postmin commutes are 10 to 20 kilometres long as against $21.6 \%$ in the real city), short and mid-range trips become the norm (88\% of trips-to-work in the postmin PMA are shorter than 10 kilometres, which is 30 points more than in the real city).

\section{Table 2}

The post-min city consequently offers the promise of major reductions in commute distances. Consistently with the estimates of much prior research, we found substantial potential for reductions in commuting distance in the PMA around $56 \%$ (Table 3 ). The average commute length is 4.3 kilometres in the post-min PMA as against 9.7 in the real city. This level of excess commuting is similar to those measured in many previous studies, ranging between $40 \%$ and $60 \%$ (Horner, 2007). So it would seem that PMA's monocentric structure, the fairly high densities in its core area and high levels of job-housing mix, 
especially compared with North-American cities, do not prevent the city experiencing quite a significant level of excess commuting. The decrease in the average commute length in the post-min PMA results in major savings of energy consumption and greenhouse gas emissions linked to urban mobility. According to our estimations, commutes in the post-min PMA consume 49\% less energy than in the real PMA and emissions are reduced by $43 \%{ }^{5}$.

\section{Table 3}

With an average commute shorter than 5 kilometres, the post-min PMA is, as one could expect, a city where more workers travel to work using soft modes of transport. However, the increase in the market share of soft modes is not huge: $9.7 \%$ of all journeys-to-work are covered using soft modes of transport in the post-min PMA, which is only 1.8 points more than in the real city. This rather moderate growth reflects the fact that the shift to the post-min PMA does not bring with it an increase in the number of the very short commutes which have the best chance of being travelled on foot or by bicycle. Commutes of 2 to 5 kilometres are substantially more frequent in the post-min PMA (50\% of all commutes in the post-min PMA as against $20 \%$ in the real city), but not those shorter than 2 kilometres (12.4\% as against $18 \%$ in the real Paris MA).

The post-min PMA is mainly a city of short $(2-5 \mathrm{~km})$ and mid-range $(5-10 \mathrm{~km})$ commutes. These two ranges combined (commutes of 2 to 10 kilometres) account for three fourths of all commutes in the post-min PMA, which is almost twice as many as in the real PMA. As the private car is very competitive over these distances, the shift to the post-min PMA is accompanied by a significant increase in car use on trips-to-work. According to our estimates, the post-min PMA sees 250,000 additional people driving to work ('car exclusively' as main transport mode) - an $11 \%$ increase (Table 4). The share of commutes travelled by car exclusively is $54.6 \%$ in the post-min PMA, which is 5.4 points more than in the real PMA. This rise is partially offset by the decrease in the number of trips combining car and public transport $(-125,000)$ - most probably, many such commutes become car-only trips in the post-min city. We can therefore estimate

\footnotetext{
${ }^{5}$ These estimations are based on unitary reference-values provided for the different modes of transport produced by the French Agency for Environment and Energy Management (Agence de l'Environnement et de la Maitrise de l'Energie - ADEME) (ADEME, 2008). See Table A2 in the appendix.
} 
the number of additional cars used on journeys-to-work in the post-min PMA at about 125,000 vehicles. It would seem that, in the case of Paris, excess commuting is not clearly the same as excess car-driving to work, since even more people would drive to work if excess commuting were eradicated.

The estimations reveal a decrease in the market share of public transport in the post-min PMA. This is mainly caused by a spectacular fall in the number of journeys-to-work travelled by rail (a loss of 420,000 passengers, taking together trips travelled by rail exclusively and those combining rail and bus, which represent a third of all passengers). Conversely, the number of commutes travelled by bus alone increases by $56 \%$, reaching more than half a million tripsto-work. On the basis of our results, the post-min PMA appears to be well-suited for light public transport, efficient on short and mid-range trips, but is not much suited to heavy rail public transport, which is most competitive on longer-range commutes.

\section{Table 4}

The results obtained with the alternative methodology, in which the likelihood of a journey-to-work being travelled by a given transport mode was estimated through Census data, are broadly convergent with these main findings. According to the estimations based on the alternative methodology, the shift to the post-min PMA would slightly increase the market shares of two-wheelers $(+29 \%)$ and private car alone $(+7.2 \%)$, while public transport alone would be less frequently used for commuting $(-2.7 \%)$. Multimodal commutes, involving more than one mode of transport, would also lose market share in the post-min PMA (-14\%).

\section{The post-min Paris Metropolitan Area is more of a two-tier city}

The modal shifts caused by the transition to the post-min city show very high differentials between geographical areas. The changes affect the different parts of the city in very different ways. Overall, the estimated modal shifts tend to consolidate existing local specificities: each mode of transport tends to reinforce its position in areas where it is currently most developed. 
In the Paris inner-city (corresponding to "Paris intra-muros"), the core of the PMA, where the residents' propensity to use soft modes of transport on trips-towork is the greatest, the shift to the post-min city prompts a sharp increase in the market share of these modes of transport ( +6.8 points). The inner-city is the only area where soft modes of transport gain ground substantially: elsewhere, they tend to stagnate. Conversely, in the central areas, where car use on tripsto-work is less common, the propensity of residents to drive to work remains low - the car even loses market share in the inner-city (the proportion of people driving to work is five points less in the post-min Paris inner-city, while the market shares of bus and soft modes rise). Only $15 \%$ of workers living in the Paris inner-city and less than $40 \%$ of those in the central suburbs go to work by car in the post-min PMA, whereas more than three quarters of inhabitants do so in the outer suburbs. The Paris inner-city is slightly affected by a growing propensity of people working in the inner-city to commute by car ( +1.6 point), but this is a modest increase compared with that observed in the inner suburbs (the modal share of the car on trips-to-work increases by 10.5 points among workers who have a job located in these areas) and in the outer suburbs (Table $5)$.

The propensity of residents to drive to work grows mostly in the areas where the car is already most widely used. The high growth areas are mostly located in the outermost suburban rings where the modal share of the car is at its highest. The proportion commuting by car increases by 14.9 points among the residents of the peripheral districts (Table 5). As one can see on Figure 3, which maps the differences in the share of car trips-to-work in the post-min Paris MA and in the observed PMA at the scale of the municipalities, the areas where the increase in the share of car in the post-min PMA surpasses ten pointspercentage (in black) are dispersed throughout the metropolitan area, especially in a 20 kilometres width band located just outside the core urban area (Paris and the neighbouring districts). So it would seem that the global increase in car use for commuting in the post-min PMA is mainly to be found outside the central areas and tends to reinforce the domination of the car in the outskirts of the city.

Ultimately, according to our findings, the post-min PMA looks even more like a two-tier city than the existing city: on the one hand, a central city ever more 
friendly to pedestrians, promoting walking, cycling and "light" public transport for the enjoyment of people living in the inner-city - who often happen to be the better-off in the case of the PMA; on the other hand, peripheral urban areas increasingly characterised by car mobility for people - often the less privileged living in the suburbs.

\section{Table 5}

\section{Figure 3}

The modal shifts triggered by the post-min Paris Metropolitan Area affect the social groups in different ways

As was observed for geographical distribution, the modal shifts triggered in the post-min Paris MA do not affect the social groups in equal proportions (Table 6). The executive managers, superior intellectual professions, intermediate professions and clerks and salesmen with high educational attainment are better served, in the sense that the post-min city gives them greater opportunities than elsewhere to travel to work using soft modes of transport (in the post-min PMA, almost a quarter of all executive managers and superior intellectual professions with high educational attainment use soft modes of transport on their trips to work). By contrast, the executive managers, superior intellectual professions and intermediate professions with low educational attainment are slightly more affected by the rise in car use for journeys-to-work. Blue-collar workers with low educational achievement are rather spared the global trend towards increased car use and more often have the opportunity to access their workplace using soft modes of transport in the post-min city - this may be related to the specific spatial structure of the job market for low skilled blue-collar workers, organized as small, more or less independent job pools rather than as one big, integrated, monocentric market. However, the picture is a little different for blue-collar workers with higher educational attainment, more of whom drive to work in the post-min PMA and do not seem to be much more likely than in the real city to travel to work using soft modes of transport. To sum up, the post-min PMA seems to redistribute the modal opportunities between social groups in a rather complex way: it combines changes that may be 
described as socially "progressive" (meaning broadly beneficial to middle-low income groups such as clerks and salesmen with high educational attainment and blue-collar workers with low educational attainment) with changes that appear less beneficial (i.e. tending to benefit middle-high income groups, such as executive managers and superior intellectual professions with high educational attainment, or to penalise members of the lower socioeconomic strata, such as clerks and salesmen with low educational attainment).

\section{Table 6}

\section{Discussion}

It may be worth starting this concluding discussion by recalling that the value of our research is mainly heuristic. The goal is to conduct explorations based on simulation techniques in order to determine the characteristics of the post-min city - the city that emerges when commutes are virtually minimised - in the field of transport. Is the post-min city a realistic model? Can we hope to see our cities align with this model in the short, medium or long-term? Obviously, these are legitimate questions, and researchers such as O'Kelly and Niedzielski (2008) developed approaches based on the fact that significant commute reduction is not an easy goal to achieve, that it may be particularly hard to attain in cities with specific spatial structure, and considering that the theoretical minimum commute is most likely a target far beyond the reach of real public policies in real cities. But from the perspective of our approach such questions can be seen as metaphysical. Theoretically, the post-min city has virtues that can establish it as a valuable model to explore, but not much is known about the characteristics of the post-min city except the fact that it is a city where average commuting distances are shorter. The aim of our research is to help to fill that void through an approach based on simulation techniques. Specifically, we tried to explore how workers would travel to work in a post-min city by comparing the modal structure of commutes in the post-min city with the reality in the case of the Paris metropolis. Whether our cities can approach the post-min horizon is a different question. However, we can make the assumption that, in some cases, the evolution of the real city towards the post-min model may produce some of the effects identified in this paper. 
With regard to the results of our research, the city of short commutes seems to represent a paradox: the post-min city, in the case of the PMA, is an urban system which generates fewer car-kilometres at the same time as more commuting by car. The post-min PMA has a very convincing balance sheet in terms of the energy consumption and environmental impact of daily mobility, but less so in terms of the number of cars running in the city. A further aggravating circumstance (from the point of view of environmental inequalities) is that the general increase in car use on journeys-to-work in the post-min PMA is combined with a widening of the gap between the inner-city where, running counter to the main trend, car driving becomes less common and gives way to soft modes of transport and light public transport, and the outer suburbs where car use gains ever more ground. The additional cars running on the roads of the post-min PMA mainly clutter up the areas where car-dependency is already high and tend to avoid inner-city Paris. However, it should be added that from the point of view of transport engineering, the fact that the additional cars in the post-min PMA mostly avoid the city-centre is certainly good news for traffic fluidity at metropolitan scale.

Our findings also suggest that in the case of the PMA, the post-min city is an urban organisation not very much suited to large public rail-based transit infrastructures. The main function of urban railway systems such as the RER (Réseau Express Régional) in the PMA is to carry commuters long distances, especially between the suburbs and the city-centre. The post-min city significantly reduces the demand for this type of journey, resulting in the decline of transport systems mainly designed for journeys of this kind. This result can be interpreted in two different ways. On the one hand, it can be seen as a positive outcome: public rail transport in the PMA is highly congested and a fall in the number of passengers could reduce congestion on the network; on the other hand, the drop in the number of commuters using public rail transit is so great that it could lead to a deterioration in service quality (e.g. reduced train frequency), a rise in costs to operators and higher fares for users. An unexpected outcome of the post-min city might be greater difficulty in meeting the demand for travel requiring large rail infrastructures. 
These findings are based on the assumption that the determinants of modal choices would affect the travel behaviour of commuters in the post-min city in the same way as in the real city. This assumption can be translated as follows: if the transition to the post-min city were to take place with today's technology and transport supply, then we might expect to witness changes similar to those revealed by our analyses. However, in all likelihood, such a shift would not leave the organisation of the urban transport system unchanged. However, instead of seeing this as a major methodological limitation, we feel that it is more helpful to see it as an opportunity for reflection and discussion. Our findings can be interpreted as empirical evidence that not only helps to spotlight the potentially problematic aspects of the city of short commuting distances, but also to identify the spheres of action where responses to the challenges raised by the post-min city can be sought. For instance, the leftward shift in the distribution of trip-to-work distances suggests that, in the post-min PMA, public transport will be forced to be highly competitive on the mid-range metric in order to compete with the car. The steep increase in demand for bus commuting in the post-min city is consistent with this latter statement, and suggests that the supply of public bus transport is a crucial issue from this perspective. Transport systems such as Bus Rapid Transit (BRT) may therefore be particularly suited to the city of short commutes. Similarly, the collapse in demand for public rail transit in the post-min city prompts thinking about the future of this network in a city where trips get shorter.

The underlying point of view implicit in our research is that the excessive presence of cars in the city is a problem and that its reinforcement is a trend to avoid. This viewpoint is based on the technical characteristics of cars in our present-day cities: many are not energy-efficient, generate pollution, occupy space when both moving and parked, travel fast and cause safety problems. If the technical specifications of the car were to be improved, there is no reason why this point of view should not be revised, as the presence of cars in cities would be less of a problem. In some respects, the electric car represents such an improvement, but it is encountering limited success in penetrating the urban market. The distances citizens travel in their day-to-day lives (too long for battery range or too short to provide value for money) may act as a limiting 
factor (Leurent and Windisch, 2011). The post-min city seems to remove this technological barrier since average commutes are shorter, and there is an increase in mid-range travel where electric vehicles perform best. One can therefore ask whether the urban model of the post-min city is not well-suited to small electric vehicles. Also, considering the abundance of trips between two and five kilometres ( $42 \%$ of all trips-to-work) in the post-min PMA, it may be that the electric vehicles best suited to the post-min city are electric two-wheelers even more than electric cars. Commute distances in the post-min city are so short in most cases that electric two-wheelers may seem a more efficient investment than electric cars. In any event, more cars in the post-min city could mean more electric mobility.

Are these observations specific to the case of the PMA, or can they be generalised to other urban contexts? Can we assume that what applies to the PMA also applies to other cities? With the same causes producing the same effects, one is tempted to respond in the affirmative with regard to cities that share the same characteristics as the PMA - i.e. public transport that is highly competitive on long distance commutes. Such cities exist, probably in significant numbers, as mentioned above. To be certain, however, calculations need to be made! As we saw, the transition to the post-min city will inevitably cause multiple and opposing modal shifts, some favourable to car use, others favourable to soft modes of transport, and the final outcome depends on the parameters. Obviously, there is no reason to assume a priori that the broad outcome would generally be a modal shift towards the car. The purpose of our research is to draw attention to some unexpected and potentially problematic dimensions of the post-min city model. Our results show here that, under certain circumstances, urban policies that seek to reduce the day-to-day distances that people travel could paradoxically lead to an increase in the number of cars operating in cities, at least in some cases. Without challenging the virtues of the post-min model from a sustainable development perspective, this result invites urban planners to continue to develop modelling tools able to detect in advance the unexpected consequences of metropolitan scale policy plans.

This discussion can be broaden to other dimensions of the post-min city. Our study focused exclusively on the impact of commute minimization on car use. 
But the reduction of commute length could have consequences on other social, environmental and economic grounds. For instance, substantially smaller commute distances could potentially result in changes in lifestyles such as an increased number of trips, related to more frequent trips to/from home at lunch time or for other purposes. From the point of view of people living in metropolitan areas, the post-min city, where most workers have their job places nearby their homes, may lead to a sort of loss of metropolitan awareness. In the real city, as many workers have their workplaces quite far from their home, the trips-to-work are amongst the main factors which push citizens to travel daily far from their neighbourhood and to spend some of their time in other areas of the city. The daily life stretches well beyond the proximity of the homeplace and this contributes to strengthen the feeling of being a part of a large metropolitan area. In the post-min city, this reality can shrink. One can also wonder whether a job market where jobseekers and job offers are matched in a way which minimizes commute length would be as efficient as a job market which operates fully at a metropolitan scale. Reduced commute distances are bound to imply a reduced number of potential interactions within the city. A metropolitan area which presents itself as a set of "urban villages" (Bertaud, 2004) can be underperforming in terms of agglomeration economies and productivity of firms, because of lower quality matches on the job market and poorer "knowledge spillover" effects, compared to a more completely integrated metropolitan area (see Duranton and Puga, 2003 for detailed hypothesis on agglomeration economies). Such ideas or proposals are all assumptions and can prove to be relevant or misleading but they still rank among the multiple issues where one can explore the rather unforeseen consequences of the post-min city.

\section{References}

Agence de l'Environnement et de la Maîtrise de l'Energie (ADEME) (2008) Efficacités énergétique et environnementale des modes de transport. Synthèse publique. Report, Paris

Banister D (2008) The sustainable mobility paradigm. Transport Policy 15: 7380

Bertaud A (2004) The spatial organization of cities: deliberate outcome or unforeseen consequence?, WP 2004-01, Institute of Urban and Regional Development, Berkeley, $C A$ 
Boussauw $\mathrm{K}$ and Witlox $\mathrm{F}$ (2009) Introducing a commute-energy performance index for Flanders. Transportation Research Part A 43: 580-591

Boussauw K, B. Derudder, et F. Witlox, (2011) Measuring spatial separation process through the minimum commute: the case of Flanders. European Journal of Transport and Infrastructure Research 11(1): 42-60

Caenen Y, Courel J, Paulo C and Schmitt D (2011) Les Franciliens utilisent autant la voiture que les transports en commun pour aller au travail, Ile-deFrance à la page $353: 1-6$

Charron M (2007) From excess commuting to commuting possibilities: more extension to the concept of excess commuting. Environment and Planning $A$ 39(5): 1238-1254

Chowdhury TA, Scott DM and Kanaroglu PS (2013) Urban form and commuting efficiency: a comparative analysis across time and space. Urban Studies 50(1): 191-207

Cropper M and Gordon P (1991) Wasteful commuting: a re-examination. Journal of Urban Economics 29: 2-13

Duranton G and Puga D (2004) Micro-Foundations of Urban Agglomeration Economies, In: J. Vernon Henderson and Jacques-François Thisse, Editor(s), Handbook of Regional and Urban Economics, Elsevier, 2004, Volume 4, Pages 2063-2117, ISSN 1574-0080, ISBN 9780444509673

Frändberg $L$ and Vilhelmson B (2011) More or less travel: personal mobility trends in the Swedish population focusing gender and cohort. Journal of Transport Geography 19(6): 1235-1244

Frost M, Linneker B and Spence N (1998) Excess or wasteful commuting in a selection of British cities. Transportation research Part A 32: 529-538

Giuliano G and Small K (1993) Is the journey to work explained by urban structure? Urban studies 30(9): 1485-1500

Hamilton BW (1982) Wasteful commuting. Journal of Political Economy 90(5): 1035-1053

Horner MW (2002) Extensions to the concept of excess commuting. Environment and Planning A 34(3): 543-566.

Horner MW and AT Murray (2002) Excess commuting and the modifiable areal unit problem. Urban Studies 39(1): 131-139

Horner MW (2008) 'Optimal' Accessibility Landscapes? Development of a New Methodology for Simulating and Assessing Jobs-housing Relationships in Urban Regions. Urban Studies 45(8), 1583-1602.

Kim S (1995) Excess commuting for two-worker households in the Los Angeles metropolitan areas. Journal of Urban Economics 38(2): 166-182

Layman C and MW Horner (2010) Comparing methods for measuring excess commuting and jobs-housing balance: an empirical analysis of land use changes. Transportation Research Record 2174: 110-117 
Lee B, Gordon P, Richardson HW and Moore II JE (2009) Commuting trends in U.S. cities in the 1990s, Journal of Planning Education and Research 29(1): 7889

Le Néchet F (2012) Approche multiscalaire de la mobilité domicile-travail en llede-France et dans la région Rhin-Ruhr. Cahiers de géographie du Québecéographie du Québec 56(158): 405-426.

Leurent F and Windisch E (2011) Triggering the development of electric mobility: a review of public policies. European Transport Research Review 3(4): 221-235.

Loo B and Chow A (2011) Jobs-housing balance in an era of population decentralization: an analytical framework and a case study. Journal of Transport Geography 19(4): 552-562

Ma K-R and Bannister D (2007) Urban spatial change and excess commuting. Environment and Planning A 39(3): 630-646

Ma K-R and Bannister D (2006) Excess commuting: a critical review. Transport Reviews 26(6): 749-767

Manning A (2003) The real thin theory: monopsony in modern labour markets. Labour Economics 10(2): 105-131

Massot M-H and Roy E (2004) Lieu de vie-lieu de travail. 25 ans d'évolution de la distance au travail. Report for ADEME, Paris: INRETS

Mayor of London (2006) Transport 2025: Transport Vision for a growing world city. Report, London

Mercier, S. (2007) Se rendre à son travail : accessibilité de l'emploi francilien selon les activités, in Mattei et Pumain (2007), Données Urbaines, volume 5, Paris, Anthropos, pp 97-111.

Merriman D, Ohkawara T and Suzuki T (1995) Excess commuting in the Tokyo metropolitan area: measurement and policy simulations. Urban Studies 32(1): 69-85

Murphy E (2009) Excess commuting and modal choice. Transportation Research Part A 43(8): 735-743

Niedzielski MA (2006) A spatially disaggregated approach to commuting efficiency. Urban Studies 43(13): 2485-2502

Nielsen TS, Hovgesen $H$ and Lassen C (2005) Exploratory mapping of commuter flows in England and Wales, In: Annual international conference RGS-IBG, London

O'Kelly ME and Lee W (2005) Disaggregate journey-to-work data: implications for excess commuting and jobs-housing balance. Environment and Planning $A$ 37(12): 2233-2252

O'Kelly ME and Niedzielski MA (2009) Are long commute distances inefficient and disorderly? Environment and Planning A 41(11): 2741-2759

Scheiner $J(2010)$ Interrelations between travel mode choice and trip distance: trends in Germany 1976-2002. Journal of Transport Geography 18(1): 75-84. 
Schwanen T, Dieleman FM and Dijst M (2001) Travel behaviour in Dutch monocentric and policentric urban systems. Journal of Transport Geography 9(3), 173-186.

Scott DM, Kanaroglou PS and Anderson WP (1997) Impacts of commuting efficiency on congestion and emissions: case of Hamilton CMA, Canada. Transportation Research D: Transport and Environment 2: 245-257

Small AK and Song S (1992) Wasteful commuting: a resolution. Journal of Political Economy 100(4): 888-898

Suzuki T and Lee S (2012) Jobs-housing imbalance, spatial correlation and excess commuting. Transportation Research Part A 46(2): 322-336

Welch TM and Mishra S (2014) Envisioning an emission diet: application of travel demand mechanisms to facilitate policy decision making. Transportation 41(3): 611-631

White MJ (1988) Urban commuting journeys are not 'wasteful'. Journal of Political Economy 96(5): 1097-1110

Yang J (2008) Policy implications of excess commuting: examining the impacts of changes in US metropolitan spatial structure. Urban Studies 45(2): 391-405

\section{Tables \& Figures (fragments)}

\section{Table 2}

Distribution of commute length in the real PMA (observed) and in the post-min PMA

\begin{tabular}{|l|l|l|}
\hline $\begin{array}{l}\text { Commute } \\
\text { length }\end{array}$ & $\begin{array}{l}\text { Observed } \\
(\%)\end{array}$ & $\begin{array}{l}\text { Post-min } \\
(\%)\end{array}$ \\
\hline $\begin{array}{l}\text { Less than 2 } \\
\text { kms }\end{array}$ & 18.2 & 12.4 \\
\hline $\begin{array}{l}\text { Between 2 } \\
\text { and 5 kms }\end{array}$ & 20.1 & 50.4 \\
\hline $\begin{array}{l}\text { Between 5 } \\
\text { and 10 kms }\end{array}$ & 19.2 & 25.2 \\
\hline $\begin{array}{l}\text { Between 10 } \\
\text { and 20 kms }\end{array}$ & 21.6 & 9.8 \\
\hline $\begin{array}{l}\text { More than 20 } \\
\text { kms }\end{array}$ & 20.9 & 2.3 \\
\hline
\end{tabular}

Calculations by authors based on data from the 1999 National Census - INSEE and from the 2001/2002 Comprehensive Transport Survey - INSEE \& DREIF.

\section{Table 4}

Number of trips-to-work by each main mode of transport and modal shares in the postmin Paris MA.

\begin{tabular}{|l|l|l|l|l|l|}
\hline $\begin{array}{l}\text { Main mode of } \\
\text { transport }\end{array}$ & $\begin{array}{l}\text { Nbr. of trips } \\
\text { post-min }\end{array}$ & $\begin{array}{l}\text { Min-Obs } \\
\text { differential } \\
\text { (volume, } \\
\text { millions) }\end{array}$ & $\begin{array}{l}\text { Min-Obs } \\
\text { differential } \\
\text { (millions) }\end{array}$ & $\begin{array}{l}\text { Modal } \\
\text { shares } \\
\text { Post }\end{array}$ & $\begin{array}{l}\text { Min-Obs } \\
\text { differential } \\
\text { (pts.\%) }\end{array}$ \\
\hline
\end{tabular}




\begin{tabular}{|c|c|c|c|c|c|}
\hline $\begin{array}{l}\text { Rail PT } \\
\text { exclusively }\end{array}$ & 0.686 & 0.179 & 21 & 14.8 & 3.9 \\
\hline $\begin{array}{l}\text { Bus } \\
\text { exclusively }\end{array}$ & 0.566 & +0.203 & +56 & 12.2 & +4.4 \\
\hline $\begin{array}{l}\text { Combination } \\
\text { Rail PT+Bus }\end{array}$ & 0.234 & 0.239 & 51 & 5.0 & -5.2 \\
\hline Car exclusively & 2.530 & +0.249 & +11 & 54.6 & +5.4 \\
\hline $\begin{array}{l}\text { Combination } \\
\text { Car+PT }\end{array}$ & 0.038 & 0.125 & 77 & 0.8 & -2.7 \\
\hline $\begin{array}{l}\text { Motorized two- } \\
\text { wheelers }\end{array}$ & 0.13 & +0.008 & +6 & 2.8 & +0.2 \\
\hline $\begin{array}{l}\text { Soft modes of } \\
\text { transport } \\
\text { (walk, bike) }\end{array}$ & 0.449 & +0.084 & +23 & 9.7 & +1.8 \\
\hline
\end{tabular}

Calculations by authors based on data from the 1999 Census - INSEE and from the 2001/2002 Comprehensive Transport Survey - INSEE \& DREIF. Min-Obs differential: difference between volumes or shares estimated for the post-min city (Min) and for the real city (Obs). The differential of volume is expressed as a percentage of values for the real city. Cf. Methodology. PT: public transport. 